\title{
CONVULSÕES INDUZIDAS POR COCAÍNA EM MODELOS ANIMAIS: UMA REVISÃO SISTEMÁTICA SOBRE ENVOLVIMENTO DAS MONOAMINAS, PARTICIPAÇÃO DO ESTRESSE OXIDATIVO E EFEITOS DE PSICOFÁRMACOS.
}

\author{
Cocaine-induced seizures in animal models: a systematic review of involvement of \\ monoamines, participation of oxidative stress and effects of psychotropic drugs.
}

\section{Francisca Cléa Florenço de Sousa, Talita Cavalcante Morais'; Natália Bitu Pinto', Nayrton Flávio Moura Rocha', Marta Maria de França Fonteles', Silvânia Maria Mendes de Vasconcelos, Glauce Socorro de Barros Viana e Danielle Silveira Macêdo ${ }^{1}$}

1 Departamento de Fisiologia e Farmacologia, Universidade Federal do Ceará, Rua Cel. Nunes de Melo 1127, 60431-970, Fortaleza, Ceará, Brasil.

*Autor para correspondência: cleaflorenco@yahoo.com.br

RESUMO: A cocaína é obtida das folhas do arbusto da coca (Erythroxylon coca) sendo utilizada como droga de abuso em diversas partes do mundo. Em doses exageradas (overdose) pode levar a convulsões, falência cardíaca ou depressão respiratória, culminando com a morte. O objetivo deste trabalho foi levantar dados na literatura sobre: o envolvimento das monoaminas, participação do estresse oxidativo e efeitos de psicofármacos nas convulsões induzidas por cocaína. Para isto, foi realizada revisão sistemática através do MEDLINE e PUBMED utilizando-se as seguintes palavras-chaves: cocaine, seizures, monoamines, oxidative stress e psychotropic drugs. Foram selecionados artigos publicados entre 1980 e 2007, que relacionavam cocaína com convulsões em modelos animais.

PALAVRAS-CHAVES: Cocaína, Convulsão, Monoaminas, Estresse oxidativo, Psicofármacos.

ABSTRACT: Cocaine is obtained from leafs of coca (Erythoroxylon coca). Its use has been widespread as abuse drug in diverse countries in the world. In overdose may lead to seizures, cardiac failure or respiratory depression leading to death. The goal of this study has been gathering data in literature about: involvement of monoamines, participation of oxidative stress, and effects of psychotropic drugs in cocaine-induced seizures.

It was conducted systematic review in the MEDLINE and PUBMED through the following key-words: Cocaine, Convulsion and monoamines, oxidative stress, and psychodrugs. It was selected papers published between 1980 and 2007, that related cocaine and convulsion in animal models.

KEYWORD: Cocaine, Seizures, Monamines, Oxidative Stress, Psychotropic drugs.

\section{INTRODUÇÃO}

A cocaína é obtida das folhas do arbusto da coca (Erythoroxylon coca) que contém em torno de $0,5 \%$ a $1 \%$ de cocaína e pode ser produtiva por períodos de 30 a 40 anos, com cerca de 4 a 5 colheitas por ano. Essa substância possui efeitos estimulantes e é comercializada sob a forma de um pó branco cristalino, inodoro, de sabor amargo e solúvel em água. O pó é obtido mediante o processo de transformação das folhas da coca em pasta de cocaína e esta em cloridrato (Platt, 1997). Geralmente, o cloridrato de cocaína é consumido por inalação, mas pode também ser absorvido pelas mucosas. Além disso, pode ainda ser injetado puro ou misturado com outras drogas (Platt, 1997). 
Sousa, F. C. F. et al./Revista Eletrônica de Farmácia Vol 5(3), 01 - 08, 2008.

A droga pertence ao grupo das substâncias simpaticomiméticas de ação indireta provocando aumento de neurotransmissores na fenda sináptica e um elevado estímulo das vias de neurotransmissão nas quais dopamina, noradrenalina e serotonina estão implicadas. É um estimulante do Sistema Nervoso Central (SNC), agindo sobre este com efeito semelhante ao das anfetaminas. Esta substância atua especialmente nas áreas motoras, produzindo agitação intensa. No plano terapêutico, foi usada como analgésico e anestésico, sendo protótipo dos anestésicos locais utilizados atualmente (Platt, 1997).

A ingestão de cocaína provoca uma sensação de euforia e prazer e produz melhora das funções motoras e intelectuais, perda da sensação de cansaço, euforia e anorexia (Pollock et al, 1991). Em doses elevadas como $90 \mathrm{mg} / \mathrm{Kg}$ (overdose) ocorre irritabilidade, agressividade, delírios e alucinações. Pode ocorrer também aumento da pressão arterial e da temperatura corporal assim como taquicardia e degeneração dos músculos esqueléticos. Este excesso de dose pode levar a convulsões, falência cardíaca ou depressão respiratória, culminando com a morte (Gay et al, 1982). Sendo as convulsões e morte as principais conseqüências relacionadas à overdose de cocaína, vale salientar que vários sistemas de neurotransmissão estão envolvidos neste fenômeno.

\section{OBJETIVOS}

Levantar dados na literatura atual sobre os aspectos farmacológicos e neuroquímicos envolvidos na convulsão induzida por overdose de cocaína, dando ênfase às alterações que ocorrem nos níveis das monoaminas cerebrais, participação do estresse oxidativo e efeitos de psicofármos nestas convulsões.

\section{METODOLOGIA}

Foi realizada uma revisão sistemática através do MEDLINE e PUBMED utilizando-se as seguintes palavras-chaves: cocaína, convulsão, monoaminas, estresse oxidativo e psicofármacos. Foram selecionados artigos publicados entre 1975 e 2007, que relacionavam cocaína com convulsões em modelos animais.

\section{Convulsões e estado de Mal Epilético induzidos por cocaína}

Crises convulsivas, por definição, são descargas sincrônicas, de grande intensidade (paroxísticas) e excessiva de um grupo de neurônios (Meldrum and Chapman et al, 1999) que são classificadas clinicamente em duas categorias denominadas parciais e generalizadas. As crises parciais originam-se em um grupo pequeno de neurônios que constituem o foco da convulsão. Desta forma, a sintomatologia depende da localização no foco no cérebro. Estas crises podem ser do tipo parcial simples (sem alteração da consciência) ou parcial complexa (com alteração da consciência). Já as crises generalizadas envolvem os dois hemisférios do cérebro desde o seu início.

As crises generalizadas podem consistir apenas de movimentos motores (mioclônicos, clônicos ou tônicos) ou uma abrupta perda do tônus (atonia). A crise generalizada mais comum é a tônico-clônica também chamada de grande mal. Um aspecto importante com relação às drogas de abuso e mais especificadamente relacionada a cocaína é a incidência cada vez maior nas emergências hospitalares de pacientes apresentado estado de convulsão e estado de mal epilético (EME) (Hanson et al, 1999). De fato, vários estudos mostram que a convulsão e o estado de mal epilético representam as principais complicações do uso de cocaína (Lason, 2001), ou seja, além de seu poder em causar vício, o abuso de cocaína está associado a conseqüências tóxicas, como convulsões e morte (O'Dell et al, 2000b). O aparecimento de convulsões e EME pode ser devido, pelo menos em parte, à redução do limiar da convulsão produzida pela cocaína, ou pode ocorrer secundariamente aos eventos cardíacos induzidos pelo SNC, assim também como ser resultado das febres altas induzidas pela droga (Roberts et al, 1980).

De um modo geral, as convulsões induzidas por cocaína se manifestam como ataques tônico-clônicos generalizados ou estado do mal epilético que são capazes de produzir modificações epileptogênicas, lesões neurológicas e psiquiátricas duradouras e morte (Kramer et al, 1990). As convulsões podem ocorrer não somente após episódios de overdose, mas também após o uso recreacional de baixas doses. Geralmente produzem estado do mal epilético minutos após a administração da droga por vias endovenosa, inalatória ou nasal; pela via oral o tempo é pouco previsível (Schranck et al, 2003).

O estado de mal epilético causado pela cocaína é de difícil controle e pode ser fatal (Campbell, 1988). Além disso, a droga pode causar outros tipos de ataques, alguns dos quais nem parecem convulsão a primeira vista. Comportamento bizarro, confusão, incoerência, movimentos repetitivos dos braços ou pernas ou boca e outros movimentos estranhos no corpo podem ser resultados de descargas elétricas em áreas específicas do cérebro (Lowenstein et al,1987; Lowenstein et al,1999).

\section{Envolvimento das Monoaminas nas convulsões}

A ação dos neurotransmissores monoaminérgicos na regulação das convulsões já foi relatada por alguns autores. Desde suas observações iniciais, pesquisas substanciais têm dado suporte à teoria de que os sistemas noradrenérgico e serotonérgico exercem efeitos inibitórios na atividade convulsivante. Esses sistemas parecem 
Sousa, F. C. F. et al./Revista Eletrônica de Farmácia Vol 5(3), 01 - 08, 2008.

regular a atividade convulsiva em relação inversa à concentração a NA e 5-HT, visto que quando os principais nervos noradrenérgicos do loco cerúleo (lócus ceruleus,LC) são lesionados, a sensibilidade à convulsão por vários agentes convulsionantes é aumentada.O inverso também parece verdadeiro,ou seja,quando a neurotransmissão noradrenérgica é aumentada devido a estimulação elétrica do LC,a atividade convulsivante desencadeada por agentes convulsivos é reduzida (Mishra et al, 1994; Sullivan \& Osorio, 1991).

Vários estudos dão suporte à teoria de que 0 aumento da suscetibilidade à convulsão pode ser conseqüência de uma redução de NA e 5-HT. Trabalhos mostram que os neurônios NA disparam durante o início da convulsão e/ou propagação e que alterações na síntese e liberação da NA, as quais ocorrem após a convulsão, podem afetar o número e severidade das convulsões recorrentes. Entretanto, existem controvérsias com relação a esta monoamina, pois enquanto alguns estudos mostram uma ação anticonvulsivante da NA, outros, mostram que o tratamento com antidepressivos, que reconhecidamente aumentam os níveis dessa monoamina, apresentam efeitos pró-convulsivantes (Peterson et al, 1985).

O mesmo ocorre em relação ao $5-\mathrm{HT}$, onde pesquisas recentes mostram que o uso de antidepressivos que aumentam os níveis desta monoamina têm como efeito adverso, no caso de overdose, o surgimento de convulsões (Zienowcz et al, 2004).

O papel dopaminérgico na regulação da atividade convulsivante parece difícil de determinar, embora este sistema pareça se comportar de forma diferente àquele observado com o noradrenérgico. Sabe-se que a dopamina se liga a dois tipos principais de receptores denominados D1 e D2 no SNC. Foi demonstrado que drogas que antagonizam o receptor D2, como Haloperidol (Ogren \& Pakh, 1993) e agonistas D1 mostram efeitos proconvulsivantes em muitos modelos de convulsão, inclusive naquelas induzidas por pilocarpina (Baroni et al,1990). Em contraste, agonistas do receptor D2, como quinpirole e lisurida, mostram atividade anticonvulsivante que é bloqueada por antagonistas deste receptor (Sousa et al,2004).

Em suma, as monoaminas se comportam de forma diferente com relação à convulsão induzida por cocaína e adicionalmente os níveis das monoaminas nas convulsões induzidas por cocaína variam ainda segundo a área cerebral estudada (Macêdo, 2005; Macêdo et al, 2004a).

Ação de drogas que interferem nos diferentes sistemas de neurotransmissão central nas convulsões induzidas por cocaína.

O mecanismo de disparo das convulsões induzidas por cocaína é complexo e diversas vias de neurotransmissão central estão implicadas, inclusive canais iônicos voltagem dependentes em vias inibitórias no córtex e hipocampo (Lason, 2001). Manipulações farmacológicas utilizando drogas que agem em diferentes sítios de ação no sistema nervoso central têm demonstrado a capacidade de algumas dessas drogas atenuarem ou potencializarem convulsões e mortes induzidas por cocaína.

\section{Drogas que interferem no Sistema Serotoninérgico}

A neurotransmissão serotonérgica parece estar bem implicada no desenvolvimento das crises convulsivas induzidas por cocaína (O'Dell et al, 2000a; Ritz \& George, 1997a). Foi demonstrado previamente que fluoxetina, um inibidor seletivo da recaptação de serotonina, dependendo da dose, apresenta efeitos diferentes nas convulsões induzidas por cocaína, visto que, em baixas doses, $10 \mathrm{mg} / \mathrm{Kg}$, possui um efeito protetor, o qual desaparece com o aumento da dose para $20 \mathrm{mg} / \mathrm{Kg}$. (Macêdo et al, 2004b).

Ketanserina e cinanserina drogas antagonistas dos receptores 5-HT2, parecem bloquear as crises convulsivas induzidas por cocaína (Ritz \& George, 1997a), enquanto a buspirona, agonista 5-HT1, não diminui o número de animais que convulsionam, porém, em baixas doses, $5 \mathrm{mg} / \mathrm{Kg}$, aumenta a porcentagem de animais sobreviventes (Macêdo et al, 2004b). 3-trifluorometilfenilpiperazínio (TFMPP), um agonista dos receptores 5-HT2, facilita as convulsões por cocaína assim como mCPP e MK212 que agem preferencialmente nos subtipos 2C, também potencializam essas ações convulsivas da cocaína (O'Dell et al,2000b). Confirmando esta estreita relação entre sistema serotonérgico e convulsão, também foi observada previamente concentração aumentada de serotonina no córtex pré-frontal de animais em que foram induzidas convulsões por cocaína (Macêdo et al, 2004a).

\section{Drogas que interferem no Sistema Dopaminérgico}

A neurotransmissão dopaminérgica parece estar relacionada na gênese das convulsões induzidas por cocaína. Estudos mostram que a pimozida, um antagonista dos receptores D2, exarcerba as convulsões induzidas por cocaína em camundongos, diminuindo a latência de início das convulsões (Macêdo et al, 2004b) enquanto, o antagonista D1, SCH23390 aumenta a latência de início das convulsões, diminui a porcentagem de animais que convulsionam e aumenta a sobrevivência dos animais utilizados no teste (Macêdo et al, 2004a). Outros estudos também enfatizam a participação do sistema dopaminérgico nas convulsões por cocaína, relatando que SKF38393, agonista D1 potencializa a convulsão, a qual diminui com a administração de Bromocriptina, agonista D2 (Macêdo et al, 2004a). 
Sousa, F. C. F. et al./Revista Eletrônica de Farmácia Vol 5(3), 01 - 08, 2008.

\section{Drogas que interferem no Sistema colinérgico muscarínico}

De uma forma geral, o sistema muscarínico está envolvido na geração de crises convulsivas, desde que drogas que aumentam a transmissão colinérgica, como fisiostigmina, ou que atuam como agonistas nos receptores muscarínicos, como pilorcarpina, induzem convulsão (Ritz \& George, 1997b)

No caso das convulsões induzidas por cocaína, trabalhos como o de Ritz \& George (1997b) mostram especificamente o envolvimento dos receptores M1 e M2-símile assim como dos receptores sigma nestas convulsões. Confirmando o papel dos receptores muscarínicos nas convulsões induzidas por cocaína, foi evidenciado (Macêdo,2005) que o tratamento prévio com pirenzepina, um antagonista M1, reduziu o numero de animais que convulsionam, embora, em contrapartida tenha diminuído o tempo de latência para a convulsão e não alterado o número de animais mortos, sugerindo um papel desses receptores apenas na indução de convulsão, não parecendo estarem relacionado com a mortalidade. Entretanto, não se pode descartar também o bloqueio dos receptores M4 pela pirenzepina, o qual está relacionado à diminuição da liberação de glicina de alguns neurônios, e que portanto, pode explicar o efeito da diminuição da latência de convulsão (Macêdo, 2005)

\section{Antidepressivos e convulsão}

Antidepressivos tricíclicos bloqueiam a recaptação de monoaminas, assim aumentando a sua disponibilidade na fenda sináptica. Trabalhos mostram que os níveis de noradrenalina e serotonina estão aumentados no córtex pré-frontal de animais que receberam doses convulsivantes, $90 \mathrm{mg} / \mathrm{Kg}$, de cocaína (Macêdo et al, 2004a). Imipramina parece ter um efeito bifásico, não apenas reduzindo o número de animais que convulsionam, mas também reduzindo as mortes em modelos animais, quando utilizadas em baixas doses como 5 $\mathrm{mg} / \mathrm{Kg}$; quando utilizada em doses maiores, dobro ou triplo, esses efeitos desaparecem levando então a uma diminuição da latência de convulsão e aumentando a mortalidade dos animais (Macêdo et al, 2004b). Este efeito pode estar associado ao próprio efeito tóxico dos antidepressivos tricíclicos de produzir convulsão (Agop et al, 2006).

\section{Lítio e convulsão}

O lítio é a droga de escolha para o tratamento de distúrbio bipolar, condição freqüentemente ligada à síndrome de abstinência de dependentes de cocaína. Em animais pré-tratados com lítio e posteriormente administrados com overdose de cocaína, o lítio, em diferentes doses, reduziu o número de animais que convulsionaram não alterando a taxa de mortes sugerindo um possível papel protetor deste agente nas convulsões induzidas por cocaína (Macêdo, 2005).

\section{Antagonistas opióides e convulsão}

Naltrexona é um antagonista opióide não seletivo que foi associado à proteção das convulsões induzidas por cocaína. Quando utilizado continuamente por nove dias, diminuiu o número de animais que convulsionaram (Braida et al, 1997). Entretanto quando administrado agudamente a naltrexona aumentou a taxa de mortalidade nos animais, sugerindo um efeito modulador dependente de tempo dos receptores opióides nas convulsões induzidas por cocaína (Macêdo et al, 2004b).

\section{Envolvimento do Estresse Oxidativo nas convulsões induzidas por cocaína}

O estresse oxidativo (EO) é o resultado da excessiva produção de espécies químicas reativas, como os radicais livres. $O$ termo radical livre faz referência a um átomo ou molécula altamente reativos que contêm um número ímpar de elétrons em sua última camada eletrônica (Halliwell, 1992; Halliwell \& Gutteridge, 1990). Os radicais livres, sendo moléculas altamente instáveis, com elétrons desemparelhados, têm grande poder oxidativo e, por conseguinte, potencial para causar danos celulares a proteínas, lipídios, carboidratos e ácidos nucléicos (Filomeni \& Ciriolo, 2006).

Sob condições fisiológicas, existem vários níveis de defesa para proteger contra esses radicais livres, incluindo a restrição da sua produção através da manutenção de um elevado gradiente de oxigênio entre o ambiente e a célula, sua remoção por antioxidantes não-enzimáticos e enzimáticos e à reparação dos danos oxidativos por mecanismos estruturais de reparação e substituição (Davies, 2000; Sies, 1997). Como 
Sousa, F. C. F. et al./Revista Eletrônica de Farmácia Vol 5(3), 01 - 08, 2008.

defesa antioxidante enzimática, temos como exemplos as enzimas Catalase, Superóxido dismutase, Glutationa reduzida e Glutationa peroxidase.

Porém, em alguns casos, essa proteção falha, devido à superprodução de radicais livres ou a deficiências na defesa antioxidante (Sies, 1997). Portanto, o estresse oxidativo é uma condição na qual as defesas celulares antioxidantes são inadequadas para detoxificar completamente os radicais livres gerados, devido à produção excessiva de espécies reativas de oxigênio, perda das defesas antioxidantes ou ambas (Davies, 2000).

Os radicais livres estão envolvidos na patogênese de várias doenças, incluindo aterosclerose, diabetes mellitus, acidente vascular cerebral, doenças inflamatórias e câncer (Plachta et al,1992;Pirozhokov et al,1992; Oberley, 1988; Fantoni \& Ward, 1982), bem como na epilepsia generalizada (Armsted et al, 1989). Algumas teorias afirmam que o estresse oxidativo pode estar relacionado com disfunção neurológica associada a doenças, incluindo a doença de Parkinson, Alzheimer, epilepsias, dentre outras (Braida et al, 1997)

A teoria do estresse oxidativo, como um mecanismo fisiopatológico, pode ser explicado pelo conceito, por vezes referido como o "oxigênio paradoxo" visto que o oxigênio é essencial para a vida aeróbica, porém, em quantidades excessivas gera radicais livres e subprodutos metabólicos que são tóxicos (Davies, 1995).

$\mathrm{Na}$ tentativa de explicar o mecanismo envolvido nas convulsões induzidas pela cocaína, alguns poucos trabalhos estudaram o papel do estresse oxidativo nestas convulsões, visto que é também reconhecido que a cocaína aumenta o estresse oxidativo e isso pode levar a neurodegeneração (Fantel \& Person, 2002). Para avaliar o papel do estresse oxidativo, são analisadas algumas enzimas de defesa do organismo e através desta análise verifica-se uma alteração ou não de sua atividade protetora contra o estresse.

Em estudo de Macêdo e Sousa et al, (2005), verificou-se que a cocaína em baixas doses, (10 e 30 $\mathrm{mg} / \mathrm{Kg}$ ), e altas (overdose), alterava a atividade da catalase em córtex pré-frontal e corpo estriado de camundongos,sugerindo-se uma importante participação da catalase nas ações da cocaína no SNC, bem como nas convulsões e morte induzidas por cocaína. Concluiu-se neste estudo que a diminuição da atividade da catalase pode estar associada a um aumento do conteúdo de peróxido de hidrogênio e possível geração de radicais hidroxilas. Esses dados indicaram uma possível participação do EO nas ações da cocaína no cérebro de camundongos.

No sentido de confirmar se realmente havia participação de estresse oxidativo nas convulsões induzidas pela cocaína, esse mesmo grupo de pesquisadoras resolveu verificar se a vitamina $\mathrm{E}$, um antioxidante que participa da defesa contra radicais livres, inibia as convulsões e morte induzidas pela cocaína. Com esse estudo (Macêdo, 2005), observou-se um efeito protetor da vitamina, visto que houve uma redução do número de animais que convulsionaram de $40 \%$ e um aumento da sobrevivência de $26,7 \%$.

\section{CONCLUSÃO}

Embora na literatura haja referências sobre o envolvimento das monoaminas, participação do estresse oxidativo e alterações associadas a fármacos que agem no SNC, nas convulsões induzidas por cocaína, estas informações não são conclusivas, havendo, portanto várias lacunas, tornando assim um campo ainda promissor para estudos posteriores na busca de se comprovar o real mecanismo de ação da cocaína na indução das convulsões.

\section{REFERÊNCIAS BIBLIOGRÁFICAS}

AGOP et al. Seizures associated with poisoning in children: tricyclicantidepressant intoxication. Pediatrics International. v.48, p. 582-585, 2006.

ARMSTEAD, W. M., et al. Cerebral superoxide anion generation during seizures in new born pigs. J. Cereb. Blood Flow Metab. v. 9, p. 175-9, 1989.

BARONE, P. et al. Dopamine D1 receptor modulation of pilocarpine-induced convulsions. Neurosci. v.34, p.206, 1990.

BRAIDA, D. et al. Naltrexone, naltrindole and CTOP block cocaine-induced sensitization to seizures and death. Peptides. v.18, p. 1189-95, 1997.

CAMPBELL, J. N. et al. Myelinated afferents signal the hyrealgesia associated with nerve injury. Pain. v.32, p.89-94, 1988.

DAVIES, K. J. Oxidative stress: the paradox of aerobic life. Biochemical Society Symposium. v.61, p. 1-31, 1995. 
Sousa, F. C. F. et al./Revista Eletrônica de Farmácia Vol 5(3), 01 - 08, 2008.

DAVIES, K. J. Oxidative stress, antioxidant defenses and damage removal, repair, and replacement systems. IUBMB Life. v. 50, p. 279-289, 2000.

FANTEL, A. G.; PERSON, R. E. Involvement of mithocondria and other free radical sources in normal and abnormal fetal development, Ann. N.Y. Acad. Sci. v.959, p. 424-433, 2002.

FANTONE, J. C.; WARD, P. A. Role of oxygen derived free radicals and metabolites in leukocyte-dependent inflammatory reactions, Am. J. Pathol. v.107, p. 397-418, 1982.

FILOMENI, G.; CIRIOLO, M. R. Redox control of apoptosis: an update. Antioxidants and Redox Signaling. v. 8, p. 2187-2192, 2006.

GAY, G. R. et al. Clinical management of acute and chronic cocaine poisoning.Ann.Emerg.Med. v. 11, p.562$572,1982$.

HALLIWELL, B. Reactive oxygen species and the central nervous system. J. Neurochem. v. 59, p. 1609-23, 1992.

HALLIWELL, B.; GUTTERIDGE, J. M. C. Role of free radicals and catalytic metal ions in humam disease: an overview. Methods Enzymol. v. 186, p. 1-85, 1990.

HANSON, G. R. et al. Distinct features of seizures induced by cocaine and amphetamine analogs.

Eur.J.Pharmacology. v. 377, p. 1-36,1999.

KRAMER, L. D. et al. Cocaine related seizures in adults. Am. J. Drug Alcohol Abuse. v. 16, p.309-17, 1990.

LASON, W. Neurochemical and pharmacological aspects of cocaine-induced seizures. Pol J Pharmacol. v. 53, p. 57-60, 2001.

LOWENSTEIN, D.H. et al. Acute neurologic and psychiatric complications associated with cocaine abuse. Am J Med. v. 83, p. 841-6, 1987.

LOWENSTEIN, D. H.; BLECK, T.; MACDONALD, R. L. It's time to revise the definition of status epilepticus.Epilepsia. v. 40, p.120-122,1999.

MACÊDO, D. S. Estudo farmacológico e de alterações neuroquímicas em córtex pré-frontal e corpo estriado de camundongos após convulsões e morte induzidas por overdose de cocaína. 2005. 298p. Tese (Doutorado em Farmacologia) - Curso de Pós-Graduação em Farmacologia, Universidade Federal do Ceará, Fortaleza.

MACÊDO, D. S. et al. Alterations in monoamines levels after cocaine-induced status epilepticus and death in striatum in prefrontal córtex of mice.Neurosci.Lett. v. 362, p.185-188, 2004a.

MACÊDO, D. S. et al. Cocaine alters catalase activity in prefrontal córtex and striatum of mice. Neuroscience Letters. v. 387, p. 56-6, 2005.

MACÊDO, D. S. et al. Effect of anxiolytic,antidepressant, and antipsychotic drugs on cocaine-induced seizures and mortality.Epilepsy Behav. p. 852-6, 2004b.

MELDRUM, B. AND CHAPMAN, A. Epileptic seizures and epilepsy. In Siegel, G. J., Agranoff, B. W.,Albers, R. W., Fisher, S. K., and Uhler, M. D. (eds.), Basic Neurochemistry. Molecular, Cellular and Medical Aspects, Lippincott Williams \& Wilkins,p.758,1999.

MISHRA, P. K. et al. C.Role of norepinephrine in forebrain and brainstem seizures: chemical lesioning of locus coeruleus with DSP-4.Exp.Neurol.,v.125,p.58-64,1994.

OBERLEY, L. W. Free radicals and diabetes, Free Radic. Biol. Med. v. 5, p. 113-124, 1988. 
Sousa, F. C. F. et al./Revista Eletrônica de Farmácia Vol 5(3), 01 - 08, 2008.

O'DELL, L. E. et al. The role of serotonin2 receptors in mediating cocaine-induced convulsions. Pharmacology Biochemistry and Behavior. v. 65, no. 4,p. 677-681,2000a.

O'DELL, L. E. et al. Molecular serotonergic mechanisms appear to mediate genetic sensitivity to cocaine induced convulsion. Brain Res. v. 863, p.213-224,2000b.

OGREN, S. O.; PAKH, B. Effects of dopamine D1 and D2 receptor agonists and antagonists on seizures induced by chemoconvulsants in mice.Pharmacol.Toxicol. v. 17, p. 213-220, 1993.

PETERSON, S. L.; TRZECIAKOWSKI, J. P.; MARY, J. S. Chronic but not acute treatment with antidepressants enhances the eletroconvulsive seizures response in rats. Neuropharmacology. v.34, p.941-6,1985.

PIROZHKOV, S. V.; ESKELSON, C. D.; WATSON, R. R. Chronic Ethanol and Cocaine-Induced Hepatotoxicity: Effects of Vitamin E Supplementation Alcoholism: Clinical and Experimental Research 16 (5) , p. 904-909, 1992.

PLACHTA, H.; BARTNIKOWSKA, E.; OBARA, A. Lipid peroxides in blood from patients with atherosclerosis of coronary and peripheral arteries. Clin. Chim. Acta. v. 211, p.101-102, 1992.

PLATT, J.J. Cocaine addiction: theory, research and treatment. Ed..Harvard University Press. p.269, 1997.

POLLOCK, D.A. et al. Discrepancies en the reportes frequency of cocaine related deaths,United States, 1983 through 1988. JAMA. v. 266, p.2233-7,1991.

RITZ, M. C.; GEORGE, F. R. Cocaine-induced convulsions: pharmacological antagonism at serotonergic, muscarinic and sigma receptors, Psychopharmacology. v. 129 , p. 299-310, 1997a.

RITZ, M. C.; GEORGE, F. R. Cocaine toxicity: concurrent influence of dopaminergic, muscarinic and sigma receptors in mediating cocaine-induced lethality, Psychopharmacology. V. 129, p. 311-321, 1997b.

ROBERTS, D. C. S. et al. Extinction and recovery of cocaine self-administration following 6-OHDA lesion of the nucleus accumbens.Pharmacol.Biochem.Beh. v.17, p.781-787,1980.

SCHRANCK, N. et al. Cocaine treatment increases expression of a $40 \mathrm{kDa}$ catecholamines-regulated protein in discrete brain regions. Synapse. v. 47, p.33-44, 2003.

SIES, H. Oxidative stress: oxidants and antioxidants. Experimental Physiology.v. 82, p. 291-295, 1997.

SOUSA, F. C. F. et al. Early withdrawal from repeated cocaine administration upregulates muscarinic and dopaminergic D2-like receptors in rat neostriatum. Epilepsy \& Behavior. v. 5, p. 852-856, 2004.

SULLIVAN, H. C.; OSORIO, I. Aggravation of penicillin-induced epilepsy em rats with LC lesion.Epilepsia,v.32,p.591-5,1991.

ZIENOWICZ, M. et al. The effect of fluoxetine in model of chemically induced seizures-behavioral and immunocytochemical study. Neurosci.Lett. v. 373, p.226-31, 2004. 
Sousa, F. C. F. et al./Revista Eletrônica de Farmácia Vol 5(3), 01 - 08, 2008. 